\title{
PEMBUATAN VALUE ADDED PRODUCT EKADO IKAN KEMBUNG DARI DESA SUNGAI RAWA KECAMATAN SUNGAI APIT KABUPATEN SIAK PROVINSI RIAU
}

\author{
Basri $^{1}$ Kurnia Sada ${ }^{1}$ Nia Zuwandha ${ }^{2}$ \\ ${ }^{1}$ Dosen Jurusan Pengolahan Hasil Laut Poltek KP Dumai \\ ${ }^{2}$ Taruna Jurusan Pengolahan Hasil Laut Poltek KP Dumai \\ *Email: tanjungbasri29@gmail.com
}

\begin{abstract}
ABSTRAK
Ikan kembung (Rastrelliger sp) merupakan ikan pelagis dengan volume produksi perikanan tangkap yang tinggi. Tingginya volume ikan kembung yang tertangkap mengharuskan nelayan maupun pedagang untuk menjaga mutu ikan. Pembuatan produk olahan lanjutan atau yang sering dikenal dengan sebutan value added product seperti pembuatan ekado ikan memiliki tujuan untuk memperpanjang daya awet dan masa simpan dari ikan. Ekado ikan adalah produk olahan hasil perikanan yang dibuat dari daging ikan cincang dengan penambahan tepung tapioka, telur dan bumbu-bumbu. Spesfikasi dari produk ini adalah adonan daging ikan dibungkus dengan kulit pangsit dan dibentuk seperti kantong yang diikat bagian atasnya dengan daun kucai. Hasil penelitian menunjukkan bahwa nilai rendemen (hasil yang bisa dimanfaatkan) yang diperoleh sebesar 91,3\%, yang artinya banyak daging ikan kembung yang bisa dimanfaatkan. Proses pengolahan Ekado ikan terdapat beberapa tahapan yang harus dilakukan yaitu penerimaan bahan baku, penimbangan, pencucian, penggilingan, penambahan bumbu, pembentukan adonan, pengukusan, pengemasan dan pelabelan, serta pemasaran produk.
\end{abstract}

Kata Kunci : Ekado Ikan, Ikan Kembung Kabupaten Siak, Riau

\begin{abstract}
Mackerel (Rastrelliger sp) is a pelagic fish with a high volume of capture fisheries production. The high volume of mackerel caught requires fishermen and traders to maintain fish quality. The manufacture of advanced processed products or what is often known as value added products such as the manufacture of fish ekado has the aim of extending the shelf life and shelf life of fish. Fish ekado is a processed fish product made from minced fish meat with the addition of tapioca flour, eggs and spices. The specifications of this product are fish meat dough wrapped in wonton skin and shaped like a bag tied at the top with chives leaves. The results showed that the yield value (usable yield) obtained was $91.3 \%$, which means that a lot of mackerel meat can be utilized. The process of processing fish Ekado has several stages that must be carried out, namely receiving raw materials, weighing, washing, grinding, adding spices, forming dough, steaming, packaging and labeling, as well as product marketing.
\end{abstract}

Keywords : Fish Ekado, Puffed Fish, Siak Regency, Riau 


\section{PENDAHULUAN}

Ikan merupakan komoditi pangan yang sangat cepat mengalami perubahan mutu jika tidak ditangani segera setelah mati. Penerapan suhu rendah dengan cara pendinginan menggunakan es dan didukung oleh ketersediaan fasilitas dan cara penerapan yang baik dan benar merupakan cara yang paling efektif untuk menghambat penurunan mutu ikan. Dengan demikian, penting dipahami bahwa rantai dingin harus dipertahankan sejak ikan mati, selama distribusi hingga pemasaran (Junianto, 2003; Safitri, 2016).

Ikan kembung (Rastrelliger sp) merupakan ikan pelagis dengan volume produksi perikanan tangkap yang tinggi. Tingginya volume ikan kembung yang tertangkap mengharuskan nelayan maupun pedagang untuk menjaga mutu ikan sebab ikan merupakan produk yang mudah mengalami kemunduran mutu. Terdapat 4 jenis ikan yang mengalami kenaikan harga yaitu bandeng, cakalang, kembung dan nila. Presentase kenaikan tertinggi diterima oleh jenis ikan kembung sebesar $6.52 \%$ (Kementerian Kelautan dan Perikanan, 2013).

Pembuatan produk olahan lanjutan atau yang sering dikenal dengan sebutan value added product seperti pembuatan ekado ikan

\section{METODE PENELITIAN}

Pelaksanaan Penelitian Politeknik Kelautan dan Perikanan Dumai Program Studi Pengolahan Hasil Laut (PHL) dilaksanakan selama 1 bulan pada tanggal 16 November s/d 16 Desember 2020 di Kecamatan Sungai Apit, Kabupaten Siak. memiliki tujuan untuk memperpanjang daya awet dan masa simpan dari ikan. Hal ini dikarenakan ikan merupakan salah satu hasil perikanan yang memiliki kadar air yang lebih tinggi dibanding daging sapi maupun daging ayam sehingga diperlukan penanganan dan pengolahan lanjutan seperti dijadikan produk value added

Salah satu yang terlibat dalam subsektor perikanan adalah pengusaha perikanan, pengusaha perikanan dalam bidang industri perikanan diantaranya pengalengan, pembekuan, pengasapan, pembuatan surimi dan industri pengolahan pangan ikan. Industri pengolahan pangan ikan adalah industri yang mengolah ikan dan bahan campuran lain menjadi bahan pangan, sebagai contoh ekado, nugget ikan, sosis, dan bakso ikan.

Ekado ikan adalah produk olahan hasil perikanan yang dibuat dari daging ikan cincang dengan penambahan tepung tapioka, telur dan bumbu-bumbu. Spesfikasi dari produk ini adalah adonan daging ikan dibungkus dengan kulit pangsit dan dibentuk seperti kantong yang diikat bagian atasnya dengan daun kucai. Tujuan dilakukannya penelitian ini yaitu untuk mengetahui proses olahan dan rendemen dari pengolahan ikan kembung.

Alat dan bahan merupakan 2 hal yang sangat penting dan menjadi pokok utama dalam pelaksanaan Penelitian. Dalam pembuatan Ekado ikan Kembung terdapat beberapa alat dan bahan yang diguanakan sebagai berikut: 
Tabel 2.Peralatan pembuatan Ekado Ikan

\begin{tabular}{cll}
\hline No & \multicolumn{1}{c}{ Peralatan } & \multicolumn{1}{c}{ Fungsi } \\
\hline 1 & Talenan & Alat pada saat penyiangan ikan \\
2 & Baskom & Wadah meletakan ikan \\
3 & Kuali & Untuk mengoreng Ekado Ikan \\
4 & Timbangan & Menimbang berat ikan \\
5 & Dandang & Untuk mengukus Adonan \\
6 & Pisau & \\
7 & Blender & Alat untuk menghaluskan ikan \\
\hline
\end{tabular}

Sumber : Data primer

Tabel 3.Bahan-bahan pembuatan otak-otak

\begin{tabular}{clc}
\hline No & \multicolumn{1}{c}{ Bahan } & Jumlah \\
\hline 1 & Ikan kembung & $1 \mathrm{Kg}$ \\
2 & Bawang putih & $30 \mathrm{gr}$ \\
3 & Bawang bombay & $50 \mathrm{gr}$ \\
4 & Tepung tapioka & $500 \mathrm{gr}$ \\
5 & Merica Bubuk & $5 \mathrm{gr}$ \\
6 & Garam & $15 \mathrm{gr}$ \\
& & $1 \mathrm{Butir}$ \\
7 & Telur & Secukupnya \\
8 & Kulit Pangsit &
\end{tabular}

Sumber : Data primer

Pembuatan Ekado Ikan harus melalui beberapa tahap yaitu: dimulai dari tahap penerimaan bahan baku, penimbangan, pencucian, penggilingan, penambahan

\section{HASIL DAN PEMBAHASAN}

Langkah pertama yang dilakukan adalah mempersiapkan peralatan yang dibutuhkan seperti pisau, timbangan, talenan, meja preparasi, panci, kompor, sendok, wajan dan blender. Alat yang digunakan harus

\section{Penggilingan}

Proses penggilingan dilakukan dengan memasukkan daging ikan ke dalam

\section{Penambahan Bumbu}

Penambahan bumbu seperti garam, gula, lada, bawang putih, bawang bombay, telur, daun bawang, tepung terigu, tepung bumbu, pembentukan adonan, pengukusan, pengemasan dan pelabelan, pemasaran. Hal ini bertujuan agar Ekado Ikan yang dihasilkan memiliki kualitas yang baik.

berasal dari bahan yang tidak mudah berkarat seperti plastik dan stainless steel. Hal ini bertujuan agar peralatan tidak mudah berkarat dan tidak mencemari produk.

mesin penggiling (blender). Proses ini bertujuan untuk mendapatkan tekstur bahan baku menjadi surimi yang siap diolah.

tapioka dan tepung maizena. Setelah ditambahkan bumbu, dilakukan proses pencampuran dengan cara diuleni hingga adonan kalis. 


\section{Pembentukan Adonan}

Adonan yang sudah kalis atau tercampur rata kemudian dibungkus dengan kulit lumpia, dilakukan secara

\section{Pengukusan}

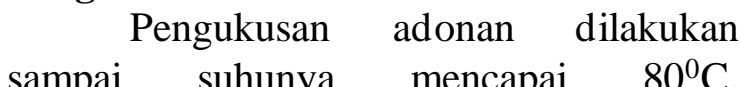
Pengukusan yang dilakukan pada suhu tersebut dimaksudkan agar adonan tidak

\section{Pengemasan dan Pelabelan}

Pengemasan dalam bentuk produk frozen, pengemasan ini berfungsi untuk melindungi produk dari kontaminasi lingkungan, memperpanjang daya simpan serta meningkatkan nilai jual dari produk. Sesuai dengan pendapat Winarno(1983); Nur (2012), kerusakan bahan pangan dapat disebabkan oleh dua hal yaitu kerusakan oleh

\section{Pemasaran}

Pemasaran adalah segala aktivitas yang dikerjakan untuk memindahkan barang dari tangan produsen ke tangan konsumen (Ilza, 2006). Produk ekado ikan dipasarkan atau dijual kepada tetangga dan sekitar Kecamatan

\section{Rendemen Ikan Kembung}

Menurut Radityo \& Darmanto (2014), rendemen merupakan rasio berat antara daging dengan berat ikan utuh. Perhitungan rendemen digunakan untuk memperkirakan berapa banyak dari tubuh ikan yang dapat digunakan sebagai bahan makanan. Hasil dari perhitungan, rendeman dari ikan kembung

\section{Uji Organoleptik Ikan Kembung}

Pengujian organoleptik merupakan cara pengujian menggunakan indera manusia sebagai alat utama untuk menilai mutu produk. Penilaian menggunakan alat indera ini meliputi spesifikasi mutu kenampakan, bau, rasa dan konsistensi/tekstur serta manual yaitu dengan menggunakan sendok, dan membentuk adonan sesuai dengan keinginan lalu di ikat dengan menggunakan daun kucai.

terlalu matang dan memiliki tekstur yang kenyal. Karena jika adonan terlalu matang maka dapat menghasilkan tekstur yang lembek.

sifat alamiah dari produk yang berlangsung secara spontan yang kedua adalah kerusakan karena pengaruh lingkungan. Oleh karena itu diperlukan pengemas untuk membatasi bahan pangan dengan lingkungan untuk mencegah atau menunda proses kerusakan sehingga suatu produk mempunyai daya tahan lebih lama untuk dikonsumsi.

Sungai Apit, yaitu dengan cara menawarkan produk ke masyarakat dari satu rumah ke rumah yang lain atau sering disebut door to door.

adalah sebesar 91,3\% hal ini menunjukkan bahwa rendemen dari ikan kembung ini sangat besar yang berarti semakin banyak bahan baku yang dapat digunakan, sesuai dengan pernyataan Yunizal et al (1998); Poernomo et al (2013), semakin besar rendemen maka semakin tinggi nilai ekonomis atau keefektifan suatu bahan.

beberapa faktor lain yang diperlukan untuk menilai produk tersebut (Badan Standarisasi Nasional).

Kegiatan organoleptik ini dilakukan terhadap ikan kembung yang ditujukan pada warna dan lendir permukaan tubuh, dan tekstur daging. Pengujian dilakukan oleh 6 orang panelis menggunakan scoresheet dengan skala nilai 1 - 9 sebagai lembar 
penilaian terhadap ikan. Interval nilai organoleptik ikan segar adalah 6,512-6,688 dan untuk penulisan akhir organoleptik ikan

\section{Desain Kemasan}

Menurut Mufreni (2016),

Kemasan adalah salah satu kunci dalam menjaga kualitas produk, yang berarti, kemasan melibatkan kegiatan mendesain dan memproduksi, untuk melindungi produk. Kemasan selalu melibatkan design agar pesan produk tersampaikan kepada konsumen, fungsi kemasan sendiri saat ini selain untuk melindungi produk juga berfungsi sebagai media pemasaran yang jitu. Terdapat 6 elemen yang harus dipenuhi ketika membuat desain produk yaitu, ukuran, bentuk, material bahan, warna, text dan merk. Warna berperan penting dalam menyampaikan pesan kognitif kepada calon pembeli. Faktor lain yang menentukan dalam desain produk adalah pemilihan text atau font yang digunakan. Font adalah contoh nyata bentuk berpengaruh terhadap persepsi (Kotler, 2003). Label yang dibuat harus sesuai dengan Undang-Undang Nomor 7 Tahun

\section{Analisa Usaha}

Produk Ekado ikan dijual kepada tetangga terdekat dengan harga Rp 25.000 / pack. Untuk mengetahui kelayakan dari usaha produk ekado ikan ini perlu dilakukan analisa usaha. Menurut Effendi (2006), analisa usaha merupakan suatu cara untuk mengetahui tingkat kelayakan dari suatu usaha. Tujuan analisa usaha adalah untuk mengetahui tingkat keuntungan, pengembalian investasi, maupun titik impas suatu usaha. Berbagai antisipasi untuk memperbaiki dan meningkatkan keuntungan juga dapat dilakukan apabila dilakukan analisa usaha.

Dari hasil perhitungan diperoleh bahwa total pengeluaran dalam proses produksi ini segar diambil nilai terkecil adalah 6,512 dibulatkan mmenjadi 7,0 (suka).

1996 tentang Pangan Pada pasal 30 ayat

2 disebutkan bahwa label, memuat sekurang-kurangnya keterangan mengenai:

1. Nama Produk

2. Daftar bahan yang digunakan

3. Berat berat atau isi bersih

4. Nama dan alamat pihak yang memproduksi

5. Tanggal, bulan dan tahun kadaluwarsa

Label dari ikan kembung ini di desain dengan menggunakan warna orange yang memiliki makna hangat, yaitu warna yang dapat menarik perhatian konsumen, selain itu juga diberi tulisan yang menarik serta barcode dan logo yang menambah daya tarik dari label ini. Pada tabel juga memenuhi syarat pelabelan. juga tersedia foto asli dari produk sehingga tidak mengecewakan pembeli karena tidak sesuai dengan harapan pembeli.

Rp 120.000, yang meliputi semua biaya bahan baku yang digunakan ketika pengolahan berlangsung. Dengan modal tersebut dihasilkan 6 pack. Jika harga satu packnya $\mathrm{Rp} 25.000$, maka total pendapatannya adalah Rp 150.000. Selain itu dilakukan juga beberapa analisa seperti rugi/laba, analisa $\mathrm{R} / \mathrm{C}$ dan analisa BEP (Break Even Point).

Analisa rugi/laba yang diperoleh sebesar Rp 70.000, yang berarti bahwa produk ekado ikan akan menghasilkan keuntungan sebesar $\mathrm{Rp} 70.000$, analisa Revenue Cost Ratio (R/C), Analisis R/C merupakan alat analisis untuk melihat keuntungan relatif

suatu usaha, nilai yang diperoleh 
sebesar 1,53, hal itu menunjukkan bahwa produk layak untuk dijalankan. karena lebih dari 1, menurut Effendi (2006), Suatu usaha dikatakan layak bila R/C lebih besar dari 1 $(\mathrm{R} / \mathrm{C}>1)$, dan yang terakhir adalah analisa Break Even Point (BEP), analisis BEP atau titik impas adalah sebuah teknik yang berguna dalam menentukan banyaknya unit yang terjual atau harga untuk mencapai titik

\section{KESIMPULAN DAN SARAN}

Kesimpulan dari Penelitian ini adalah sebagai berikut :

1. Dalam melakukan pengolahan Ekado ikan terdapat beberapa tahap yang harus dilakukan yaitu penerimaan bahan baku, penimbangan, pencucian, penggilingan, penambahan bumbu, pembentukan adonan, pengukusan,

\section{Saran}

Saran yang perlu disampaikan untuk Penelitian adalah sebagai berikut:

1. Kepada peneliti yang akan melakukan kegitan penelitian tentang value added khususnya Ekado Ikan Kembung untuk mempersiapkan diri sebaik-baiknya dengan banyak mempelajari dari jurnal

\section{DAFTAR PUSTAKA}

[BSN] Badan Standarisasi Nasional. 2013. SNI2729:201. Lembar PenilaianOrganoleptik Ikan Segar. Badan Stand arisasi Nasional : Jakarta

Anjarsari. 2010. Pangan Hewani Fisiologi Pasca Mortem dan Teknologi, Graha

Arif, Suadi. 2000. Penerimaan Bahan Baku. BP STIE YKPN. Yogyakarta.

Hulalata A, Daisy M.M, Rastutu Wp. 2013. Studi Pengolahan CumiCumi (Loligo sp.) Asin Kering Dihubungkan dengan Kadar Air dan impas (Muchson, 2017). BEP terbagi menjadi dua yaitu BEP harga dan BEP produksi, BEP harga menunjukkan harga terendah dari produk yang dihasilkan sedangkan BEP produksi adalah menggambarkan produksi minimal yang harus dihasilkan. BEP harga dari usaha ekado ikan ini adalah Rp 20.000, sedangkan BEP produksi adalah sebanyak 6 packs.

pengemasan dan pelabelan, serta pemasaran produk.

2. Hasil penelitian menunjukkan bahwa nilai rendemen (hasil yang bisa dimanfaatkan) yang diperoleh sebesar $91,3 \%$, yang artinya banyak daging ikan kembung yang bisa dimanfaatkan.

dan video-video karena minimnya pengetahuan tentang fungsi dari bahan tambahan pangan.

2. Sebaiknya untuk Penelitian dilakasanakan di perusahaan agar peneliti memahami prosedur pengolahan value added yang baik yang menjamin menambah wawasan.

Tingkat Kesukaan Konsumen.

Jurnal Media Teknologi Hasil

Perikanan. Vol 1(2). 26-33.

Julinar , Ester L, Fatma. 2005. Pengaruh Proses Pengukusan Terhadap Daya

Awet Rending Daging Sapi yang

Dikemas. Jurnal Penelitian Sains. No 18. 58- 68.

Junianto. 2003. Teknik Penanganan Ikan.

Jakarta: Penebar Swadaya.

Keputusan Menteri Kelautan dan Perikanan Republik Indonesia Nomor KEP. 52A/KEPMEN-KP/2013 Tentang Persyaratan Jaminan Mutu dan Keamanan Hasil Perikanan pada Proses Produksi, Pengolahan dan Distribusi. 
Jakarta: Kementerian Kelautan dan Perikanan.

Kotler, P., \& De Bes, F. T. (2003). Lateral marketing: New techniques for finding breakthrough ideas. John Wiley \& Sons.

Muchson M. 2017. Entrepreneurship (Kewirausahaan). Jakarta: Guepedia.

Mufreni, A. N. (2016). Pengaruh Desain Produk, Bentuk Kemasan Dan Bahan Kemasan Terhadap Minat Beli Konsumen (Studi Kasus Teh Hijau Serbuk Tocha). Jurnal Ekonomi Manajemen, 2(2), 48-54.

Nur, M. (2012). Pengaruh cara pengemasan, jenis bahan pengemas, dan lama penyimpanan terhadap sifat kimia, mikrobiologi, dan organoleptik sate bandeng (Chanos chanos). Jurnal Teknologi \& Industri Hasil Pertanian, 14(1), 1-11.

Nurjanah, RR. Nitibaskara dan E. Madiah. 2005. Pengaruh Penambahan Bahan Pengikat terhadap Karakteristik Fisik Otak-Otak Ikan Sapu-Sapu (Liposarcus pardalis).Buletin Teknologi Hasil Perikanan. Vol. VII No. 1.

Poernomo, D., Suseno, S. H., \& Subekti, B. P. (2013). Karakteristik fisika kimia bakso dari daging lumat ikan layaran (istiophorus orientalis). Jurnal Pengolahan Hasil Perikanan Indonesia, 16(1).

Radityo, C. T., \& Darmanto, Y. S. (2014). Pengaruh Penambahan Egg White Powder Dengan Konsentrasi 3\% Terhadap Kemampuan Pembentukan Gel Surimi Dari Berbagai Jenis Ikan. Jurnal Pengolahan dan bioteknologi hasil perikanan, 3(4), 1-9.

Radityo, Cancerizky Trigutomo, and Y. S. Darmanto. "Pengaruh Penambahan
Egg White Powder Dengan Konsentrasi 3\% Terhadap Kemampuan Pembentukan Gel Surimi Dari Berbagai Jenis Ikan." Jurnal Pengolahan 1-9 Ilmu, Bandung.

Safitri, E. (2016). Pengaruh Penambahan Karagenan Terhadap Kandungan Serat Kasar dan Peningkatan Nilai Gel Strength Pada Produk Kamaboko Dari Komposit Ikan Belanak (Mugil cephalus) dan Ikan Mujair (Oreochromis mossambicus) (Doctoral dissertation, Universitas Airlangga).

Setiawan AT. 2016. Laporan Praktikum Teknologi Pengolahan PanganTeknologi Pengolahan Daging dan Ikan "Kamaboko". Makalah.

Sugiyono. (2017). Metode Penelitian Kuantitatif, Kualitatif, dan R\&D. Bandung: Alfabeta, CV.

Wijandi, Soesarsono. 2003. Penerimaan dan Persiapan Bahan Baku Udang.

Winarno, F.G. (1983) Enzym pangan 115 pp. Jakarta, PT Gramedia.

Yunizal, W. S. (1998). Penanganan ikan segar. Jakarta. Instalasi Penelitian Perikanan Laut Sipil. 